\title{
A Series-Resonant Charge-Pump-Based Rectifier with Inherent PFC Capability
}

\author{
Ammar, Ahmed Morsi; Spliid, Frederik Monrad; Nour, Yasser; Knott, Arnold
}

Published in:

Proceedings of 2019 IEEE 20th Workshop on Control and Modeling for Power Electronics

Link to article, DOI:

10.1109/COMPEL.2019.8769705

Publication date:

2019

Document Version

Peer reviewed version

Link back to DTU Orbit

Citation (APA):

Ammar, A. M., Spliid, F. M., Nour, Y., \& Knott, A. (2019). A Series-Resonant Charge-Pump-Based Rectifier with Inherent PFC Capability. In Proceedings of 2019 IEEE 20th Workshop on Control and Modeling for Power Electronics (pp. 1-5). IEEE. https://doi.org/10.1109/COMPEL.2019.8769705

\section{General rights}

Copyright and moral rights for the publications made accessible in the public portal are retained by the authors and/or other copyright owners and it is a condition of accessing publications that users recognise and abide by the legal requirements associated with these rights.

- Users may download and print one copy of any publication from the public portal for the purpose of private study or research.

- You may not further distribute the material or use it for any profit-making activity or commercial gain

- You may freely distribute the URL identifying the publication in the public portal 


\title{
A Series-Resonant Charge-Pump-Based Rectifier with Inherent PFC Capability
}

\author{
Ahmed M. Ammar, Frederik M. Spliid, Yasser Nour and Arnold Knott \\ Department of Electrical Engineering \\ Technical University of Denmark \\ Kongens Lyngby, Denmark \\ \{ammma, frmsp, ynour, akn\}@elektro.dtu.dk
}

\begin{abstract}
This paper presents a power factor correction (PFC) rectifier for single-phase offline converters. With the addition of a charge pump circuit comprised of a capacitor and a diode to a class-DE series-resonant converter, PFC is achieved inherently. The converter operation is based on soft-switching, and a $1 \mathrm{MHz}$ $50 \mathrm{~W}$ prototype employing wide bandgap devices is implemented, achieving a power factor of 0.99 and a total harmonic distortion (THD) of $8.6 \%$, at an efficiency of $84 \%$, with substantially low input current harmonic magnitudes compared to the limits set by the IEC 61000-3-2 standard.
\end{abstract}

Keywords-AC-DC power conversion, rectifiers, power factor correction, resonant power conversion, wide bandgap semiconductors.

\section{INTRODUCTION}

With the recent advancements in industrial electronics that aim for added performance, reliability, and portability, there exists a great demand for new technologies in power converters that can cope with such trend. Pulse-width-modulated (PWM) converters have been the primary candidate for offline converters for years, thanks to their high efficiency and power quality. However, they typically operate at low frequencies in order to limit the switching losses, as their operation is based on hard-switching. On the other hand, resonant converters allow for the utilization of soft-switching techniques through the intrinsic alternating behavior of the currents and voltages through the switches, thus expensing substantially lower switching losses, making them a good candidate for operation at higher frequencies, which has many benefits including the smaller sizes for the passive components, higher power densities, higher loopgain bandwidths, and faster transient responses. This has led to the investigation of their adoption into different applications typically dominated by PWM converters [1]-[5].

The typical solution for offline converters is a two-stage architecture, as shown in fig. 1, where the first stage is an ACDC power factor correction (PFC) rectifier, followed by an energy storage capacitor to filter the double-the-line (100/120 $\mathrm{Hz}$ ) frequency component, while the second stage is a DC-DC converter providing the voltage and current levels that apply to the load electrical characteristics. This conversion has to comply with a number of regulations dictating the shape of the input current and harmonic limits to reduce the mains voltage distortion [6][7].

This paper presents a resonant $\mathrm{PFC}$ rectifier for the first stage in single-phase offline converters. The proposed rectifier, shown in fig. 2, incorporates an input filter and bridge, a charge pump

This project has received funding from the European Union's Horizon 2020 research and innovation programme under grant agreement No 731466.

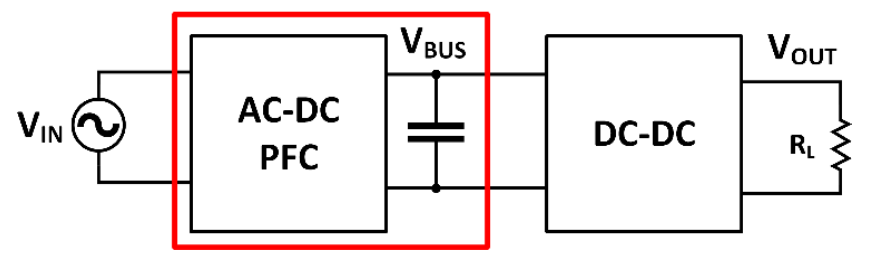

Fig. 1. Offline converter structure. The red box outlines the focus of this work.

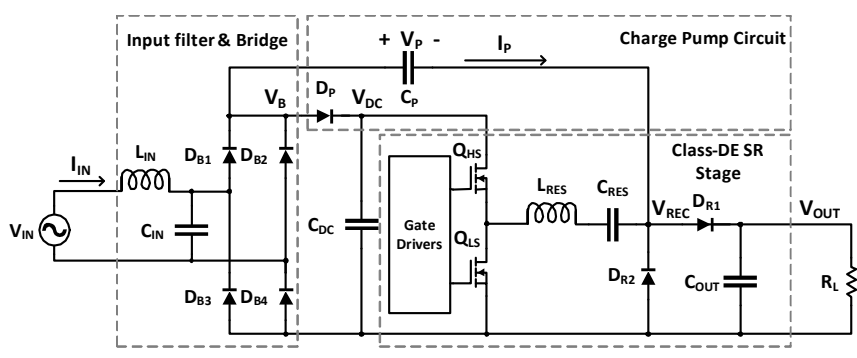

Fig. 2. Proposed PFC rectifier.

circuit, a DC energy storage capacitor, and a class-DE seriesresonant converter.

The paper is organized as follows. Section II overviews the principle of operation. The implementation process is illustrated in section III. Experimental results and waveforms are presented in section IV. Eventually, conclusion is provided in section V.

\section{PRINCIPLE OF OPERATION}

\section{A. Class-DE Resonant Stage Operation}

A resonant converter is comprised of two stages [8], as shown in fig. 3. First, an inverter that employs a switch network which converts the DC (or low frequency $\mathrm{AC}$ ) input to a high frequency $\mathrm{AC}$ output, followed by a resonant tank that provides $\mathrm{AC}-\mathrm{AC}$ gain. The second stage is a high frequency $\mathrm{AC}-\mathrm{DC}$ rectifier, where energy is tapped off the resonant tank and delivered to the load. In this work, a class-DE stage is used in the converter, which combines the low-voltage stress of class-D converters and the zero voltage switching (ZVS) capabilities of class-E converters [9]. Accordingly, the half-bridge switches are rated for the converter peak input voltage, and with a proper switching frequency and dead-time adjustment, the resonant tank current charges/discharges the output capacitances of the switches, such that their voltages reach the appropriate rail voltage before switching the gate, thus ensuring ZVS. That, in turn, allows for design at higher switching frequencies while achieving high efficiencies. 


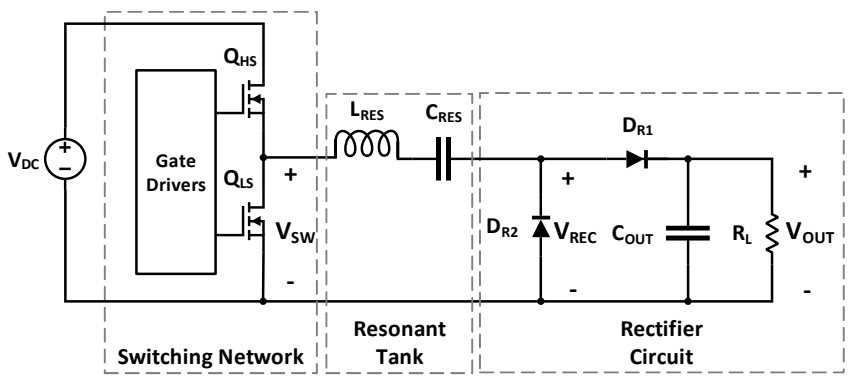

Fig. 3. Class-DE series-resonant converter.

\section{B. Charge Pump Circuit Operation}

A charge pump electronic ballast circuit was reported in [10]. Through the addition of a capacitor and a diode to a conventional high-frequency inverter circuit, the input current can be regulated to follow the input voltage. In this design, a series-resonant inverter circuit is used and a high-frequency rectifier is added for enabling use in AC-DC converters, where the energy storage capacitor is moved to the converter input to allow for soft-switching operation with the varying AC line voltage.

An equivalent circuit for the charge pump is shown in fig. 4, with $C_{P}$ and $D_{P}$ referring to the pump capacitor and diode, $D_{B}$ to the input bridge, $\mathrm{C}_{\mathrm{DC}}$ to the energy storage capacitor, while the rectifier input, to which the pump capacitor is coupled, is modelled by an independent high frequency voltage source $\mathrm{V}_{\mathrm{REC}}$. The $\mathrm{DC}$ capacitor $\mathrm{C}_{\mathrm{DC}}$ is designed in accordance with the pump capacitor $C_{P}$, such that the voltage $V_{D C}$ is always higher than $\mathrm{V}_{\mathrm{IN}}$, and thus the diode bridge $\mathrm{D}_{\mathrm{B}}$ and the pump diode $\mathrm{D}_{\mathrm{P}}$ do not cross-conduct. Consequently, the input current is equal to the positive charging current of the pump capacitor $C_{P}$.

Fig. 5 shows the low-frequency operation of the pump circuit, where the pump capacitor is charged and discharged within the fall and rise times of $V_{\text {REC }}$ respectively, and the charge $\Delta \mathrm{Q}_{\mathrm{P}}$ is proportional to the voltage difference across the capacitor $V_{P}$, which varies between a low-frequency high-value $V_{P}$ high and a constant low-value $\mathrm{V}_{\mathrm{P} \text { _low }}$. The circuit design ensures that the charge variation of $\mathrm{C}_{\mathrm{P}}$, which is proportional to the voltage variation across it $\left(V_{P_{\text {high }}}-V_{P_{-} \text {low }}\right)$, follows the input voltage $V_{I N}$ across the line cycle $(50 / 60 \mathrm{~Hz})$. Accordingly, the average input current follows the input voltage and a unity power factor can ideally be obtained.

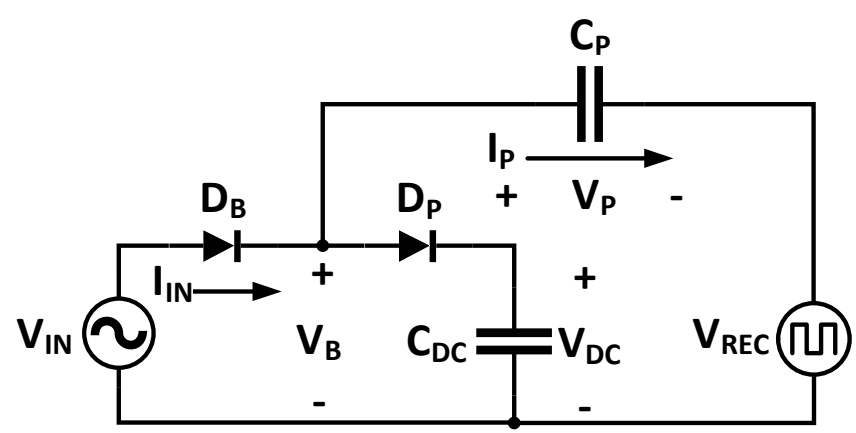

Fig. 4. Charge pump equivalent circuit.

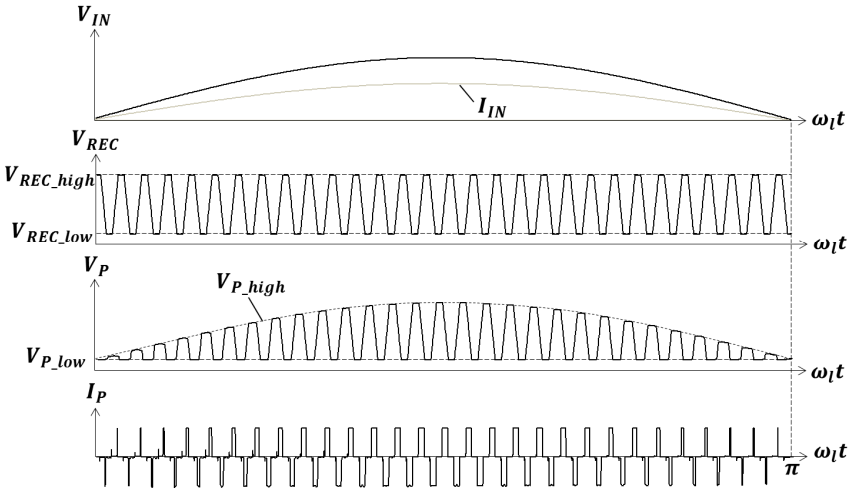

Fig. 5. Low-frequency operation across half a line cycle $(50 \mathrm{~Hz})$.

Fig. 6 shows the high-frequency operation across two switching cycles, and includes waveforms illustrating the converter operation at the maximum power point $\left(\omega_{l} t=\pi / 2\right.$, with $\omega_{l}$ being the line frequency) to illustrate the charge pump circuit operation. Across every switching cycle, at steady-state, the operation spans four intervals as follows.

In the first interval, the voltage $V_{B}$ is lower than the $D C$ capacitor voltage $V_{D C}$ and higher than the input voltage $V_{I N}$, so both the diode bridge and the pump diode are off and no current flows through the pump capacitor $C_{P}$ and the voltage $V_{P}$ is constant $\left(\mathrm{V}_{\mathrm{P}_{-} \text {low }}\right)$. The $\mathrm{V}_{\text {IN }}$ waveform in figure refers to the voltage on the node interfacing the LC-filter and the diode bridge.

The second interval takes place across the fall time of $V_{\text {REC }}$. Once $V_{R E C}$ starts to decrease, $V_{B}$ has to decrease along, until $D_{B}$ gets forward biased and $V_{B}$ gets pulled to $V_{I N}$. While $V_{R E C}$ continues decreasing, with $V_{B}$ constant (as the grid frequency is significantly lower than the frequency of $V_{R E C}$ ), $V_{P}$ increases and $C_{P}$ is charged by the line current $\mathrm{I}_{\mathrm{IN}}$, until $\mathrm{V}_{\mathrm{REC}}$ reaches its low-value and $V_{P}$ reaches its high-value, where

$$
V_{P \_h i g h}=V_{I N}-V_{R E C \_l o w}
$$

The third interval begins once $V_{\mathrm{REC}}$ settles at the low-value, where $C_{P}$ stops charging while $D_{P}$ still blocks. Similar to the first interval, no current flows through the pump capacitor and $V_{P}$ is constant.

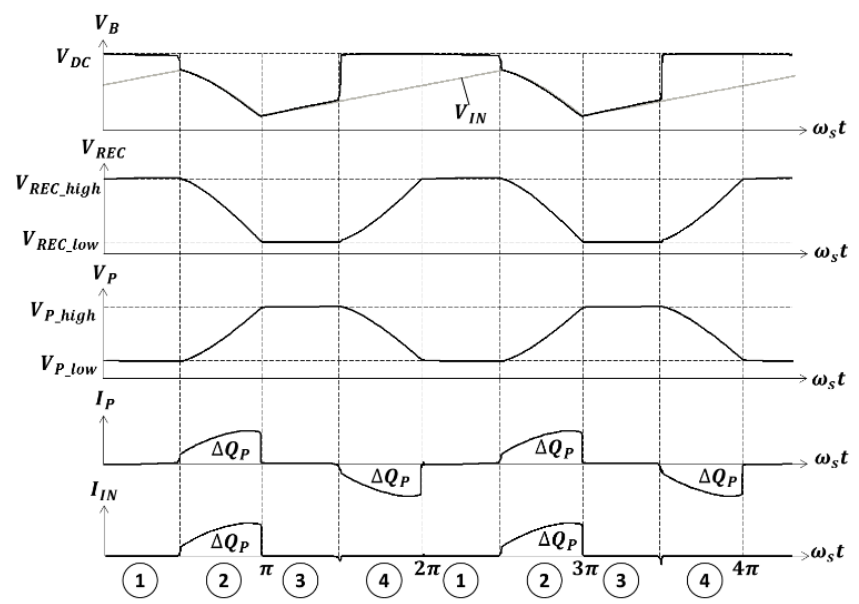

Fig. 6. Operation across two switching cycles. 
Eventually, the fourth interval takes place across the rise time of $V_{R E C}$. Once $V_{R E C}$ starts to increase, $V_{B}$ has to increase along until $D_{P}$ gets forward biased and $V_{B}$ gets pulled to $V_{D C}$. While $V_{R E C}$ continues increasing, with $V_{D C}$ constant, $V_{P}$ decreases and $C_{P}$ discharges into the resonant tank, until $\mathrm{V}_{\mathrm{REC}}$ reaches its highvalue, $V_{R E C}$ high, and $V_{P}$ reaches its low-value, where

$$
V_{P_{-} \text {low }}=V_{D C}-V_{R E C \_ \text {high }}
$$

By the end of the fourth interval, operation enters interval 1 again and the cycle repeats. The analysis shows that the input current is discontinuous and only flows into the circuit during the second interval.

For a series-resonant converter, the voltage $V_{\text {REC }}$ varies between $\mathrm{V}_{\text {OUT }}$ and $0 \mathrm{~V}$, where (1) and (2) can be evaluated as follows

$$
\begin{gathered}
V_{P_{\perp} \text { high }}=V_{I N}-V_{R E C_{-} \text {low }}=V_{I N}-0=V_{I N} \\
V_{P_{-} \text {low }}=V_{D C}-V_{R E C_{-} \text {high }}=V_{D C}-V_{O U T}
\end{gathered}
$$

The equations show that the high-values for the voltage across the pump capacitor take the envelope of the input voltage, while the low-values take the envelope of the difference between the resonant converter input and output voltages, which can be considered constant in high frequency. Across one switching cycle, the variation of charge in the capacitor is

$$
\begin{aligned}
\Delta Q_{P}= & C_{P} \cdot \Delta V_{P}=C_{P}\left(V_{P_{\_} \text {high }}-V_{P_{-} \text {low }}\right) \\
& =C_{P}\left(V_{I N}-V_{D C}+V_{\text {oUT }}\right)
\end{aligned}
$$

The pump capacitor charging current, which is equal to the input current, averaged across one switching cycle is equal to

$$
I_{I N}=\frac{\Delta Q_{P}}{T_{S}}=f_{S} \cdot \Delta Q_{P}=f_{S} \cdot C_{P}\left(V_{I N}-V_{D C}+V_{\text {OUT }}\right)
$$

where $f_{s}$ is the converter switching frequency. Considering that the class-DE stage operates near resonance with a high gain close to 1 , the difference between $V_{D C}$ and $V_{\text {OUT }}$ will be very small. Therefore, at steady state, for a constant switching frequency, the pump capacitor charging current, and accordingly the input current, become proportional to the input voltage, resulting in a high power factor and low total harmonic distortion (THD).

\section{IMPLEMENTATION}

A prototype is designed and implemented, targeting low to mid power range applications supplied from European mains. A switching frequency of $1 \mathrm{MHz}$ is specified for the design, as it constitutes a good trade-off between converter size and efficiency, with respect to the range of frequencies that the stateof-the-art magnetic materials allow for. The converter is implemented and assembled on a two-layer printed circuit board (PCB). Fig. 7 shows a photograph of the implemented prototype power stage.

Considering the charge pump circuit operation, high frequency $\mathrm{AC}$ current runs through the input bridge, which is implemented using four fast-recovery diodes. In addition, as the resonant tank carries both the charge pump circuit current as well as the current to the output load, high current stress takes place at the peak of the input power, which requires custom design of the resonant inductor. For such application with high



Fig. 7. Prototype power stage.

frequency $\mathrm{AC}$ current, the choice of the magnetic material is of key importance. Fig. 8 shows a comparison of several highfrequency magnetic materials in terms of core losses at $1 \mathrm{MHz}$ [11][12]. The 3F46 material is chosen as it shows the lowest core losses at the operational switching frequency. The inductor is designed with 52 turns of two parallel layers of $20 * 0.05 \mathrm{~mm}$ Litz wire wound on an EFD 25/13/9 core. An airgap of $1.2 \mathrm{~mm}$, distributed across the three legs of the core, adjusted the desired inductance.

With respect to the selection of switches, fig. 9 shows a comparison based on datasheet parameters between the best-inclass switches figures of merit [13]-[15], where gallium nitride FETs show superior performance in that voltage range compared to the silicon super-junction and silicon carbide counterparts. Device 6 (GS66502B) is used for the inverter halfbridge design. For the rectifier side, silicon carbide schottky diodes (GB01SLT06-214) are employed, as they result in higher efficiency compared to the silicon high-voltage counterparts.

Table I lists the proposed converter power-stage bill of materials (BOM). The switches gate driving circuit is comprised of a digital isolator (Si8610BC by Silicon Labs) and a gate driver (UCC27611 by Texas Instruments) for each of the high side and low side switches. For the high side driver supply, a bootstrap network of a diode (GB01SLT06-214, SiC Schottky) and a capacitor $(1 \mu \mathrm{F}$, ceramic $\mathrm{X} 7 \mathrm{R})$ is used, in addition to a peripheral

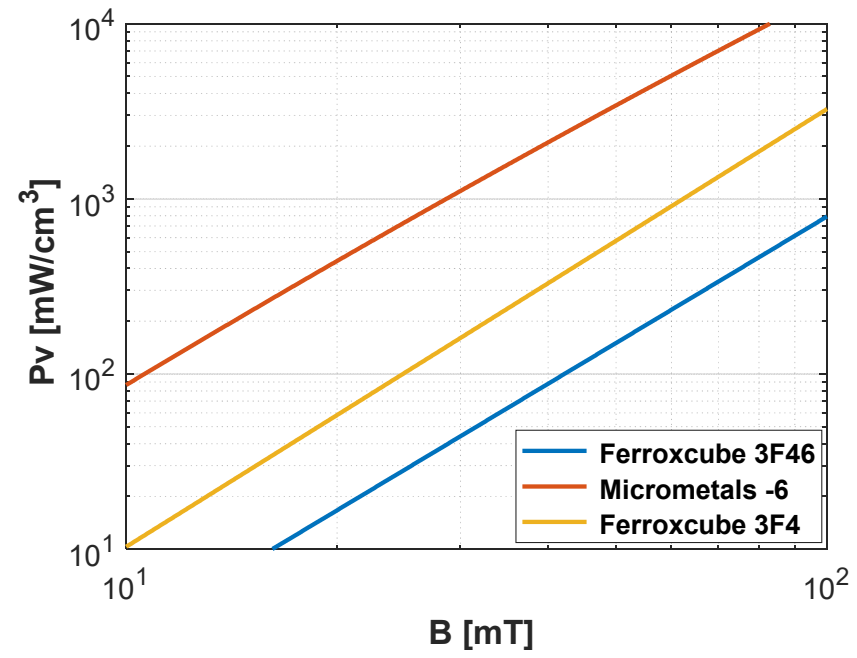

Fig. 8. Core power loss density (Pv) vs. magnetic flux density (B) for different magnetic materials at $1 \mathrm{MHz}$. 


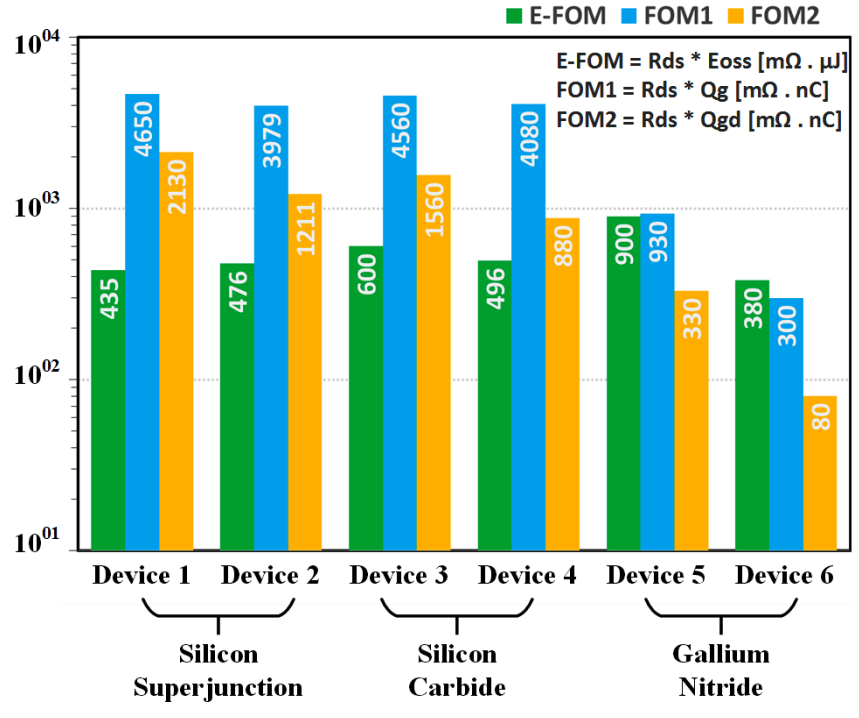

Fig. 9. Summary of the best-in-class switching devices figures of merit.

solution comprised of isolated power supplies (MTE1S0506MC by Murata), and both circuits are equally operational.

\section{EXPERIMENTAL RESULTS}

\section{A. Lab Setup}

A thermal camera (Flir T650SC) continuously monitors the converter operation and a $1 \mathrm{GHz}$ scope (LeCroy Wavesurfer 104MXS-B) displays the high frequency signals including switching node voltage, inductor current, and gate-signals, where the dead-time is adjusted and fixed at a point where softswitching is achieved and the average devices temperature is minimal. Another $200 \mathrm{MHz}$ scope (LeCroy Wavesurfer 24XsA) is used to display the low frequency signals, which include the input and output voltages and input current. A low voltage DC power supply (Rohde \& Schwarz HMP2020) supplies the driving circuit, while a high voltage $\mathrm{AC}$ power supply (Keysight AC6802A) emulates the AC mains. A $120 \mathrm{MHz}$ dual-channel waveform generator (Keysight 33622A) generates the driving circuit signals. A DC electronic load (Itech IT8812B) acts as an active load for the circuit under test. Finally, a precision power analyzer (N4L PPA5530) measures efficiency, power factor, displacement factor, THD, and the magnitudes of input current harmonics.

TABLE I. PROPOSED CONVERTER BOM

\begin{tabular}{c|c|c}
\hline Component & Value & Type \\
\hline \hline $\mathrm{L}_{\mathrm{IN}}$ & $100 \mu \mathrm{H} / 0.5 \mathrm{~A}$ & Inductor \\
\hline $\mathrm{C}_{\mathrm{IN}}$ & $2 * 15 \mathrm{nF} / 450 \mathrm{~V}$ & Ceramic $(\mathrm{C} 0 \mathrm{G})$ \\
\hline Diode Bridge & $4^{*} \mathrm{ESH} 1 \mathrm{GM} \mathrm{RSG}$ & Si Fast Recovery \\
\hline $\mathrm{C}_{\mathrm{DC}}$ & $1 * 10 \mu \mathrm{F} / 450 \mathrm{~V}$ & Electrolytic \\
& $3 * 0.1 \mu \mathrm{F} / 450 \mathrm{~V}$ & Ceramic $(\mathrm{C} 0 \mathrm{G})$ \\
\hline $\mathrm{D}_{\mathrm{P}}$ & $\mathrm{RF} 201 \mathrm{LAM} 4 \mathrm{~S}$ & Si Fast Recovery \\
\hline $\mathrm{C}_{\mathrm{P}}$ & $2 * 680 \mathrm{pF} / 500 \mathrm{~V}$ & Ceramic $(\mathrm{C} 0 \mathrm{G})$ \\
\hline $\mathrm{Q}_{\mathrm{HS}}, \mathrm{Q}_{\mathrm{LS}}$ & $\mathrm{GS} 66502 \mathrm{~B}$ & GaN Switches \\
\hline $\mathrm{L}_{\mathrm{RES}}$ & $152 \mu \mathrm{H} / 1.7 \mathrm{~A}$ & Custom design \\
\hline $\mathrm{C}_{\mathrm{RES}}$ & $220 \mathrm{pF} / 3 \mathrm{kV}$ & Ceramic $(\mathrm{C} 0 \mathrm{G})$ \\
\hline $\mathrm{D}_{\mathrm{R} 1}, \mathrm{D}_{\mathrm{R} 2}$ & $\mathrm{~GB} 01 \mathrm{SLT} 06-214$ & SiC Schottky \\
\hline $\mathrm{C}_{\mathrm{OUT}}$ & $2 * 15 \mathrm{nF} / 450 \mathrm{~V}$ & Ceramic $(\mathrm{C} 0 \mathrm{G})$ \\
\hline
\end{tabular}

\section{B. Results}

The converter is tested for operation from $230 \mathrm{~V}_{\mathrm{RMS}}$, achieving $50 \mathrm{~W}$ of output power, with an efficiency of $84 \%$, a power factor of 0.99 and a THD of $8.6 \%$ at $0.96 \mathrm{MHz}$. Fig. 10 shows a scope capture for the switching node voltage, the resonant tank current, and the signals to the gate drivers at fullload operation. The capture is taken with infinite persistence to visualize the variations across the input voltage range, which is the low-frequency ripple on the DC capacitor voltage. The switching node voltage $\mathrm{V}_{\mathrm{Sw}}$ is measured using a $500 \mathrm{MHz} 10 \mathrm{x}$ voltage probe with $9 \mathrm{pF}$ capacitance, while the resonant circuit current $\mathrm{I}_{\mathrm{RES}}$ is measured using a $50 \mathrm{MHz}$ current probe (LeCroy AP015). The figure illustrates inductive mode of operation, with the resonant current lagging the switching node voltage. The driving signals are synchronized with the same duty-cycle and extended dead-time to avoid cross conduction between the two switches and achieve ZVS. It is noted that the converter is partially soft-switching for the low voltages across the DC capacitor, which can be alleviated by employing a larger energy storage capacitor $\left(\mathrm{C}_{\mathrm{DC}}\right)$.

Fig. 11 shows the input voltage and current and the output voltage at full-load. The input voltage is displayed using a high voltage differential probe (Testec SI 9001), while the input current is measured using a $50 \mathrm{MHz}$ current probe (Hioki CT6700), and the output voltage is measured using a $500 \mathrm{MHz}$ voltage probe with $9 \mathrm{pF}$ capacitance. The figure shows an almost sinusoidal input current with a phase difference of $5.7^{\circ}$ with the input voltage, and an average output voltage of $300 \mathrm{~V}$.

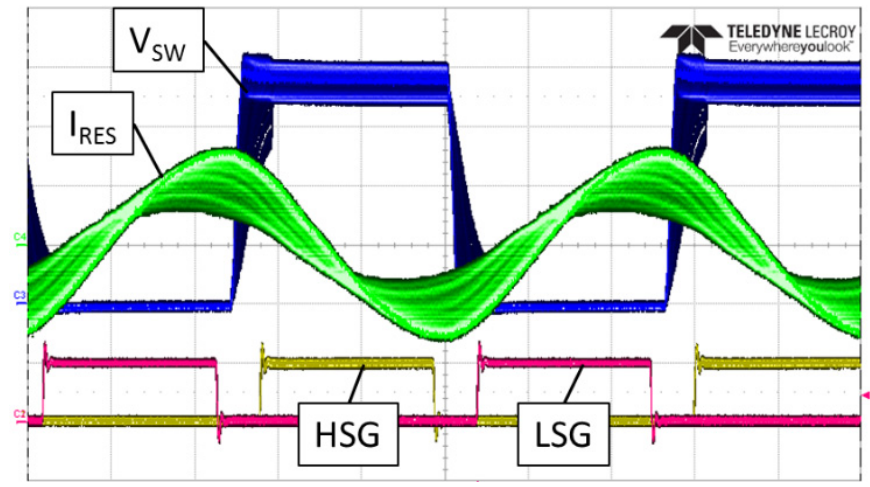

Fig. 10. Scope image for the resonant tank waveforms $\left(\mathrm{V}_{\mathrm{SW}} 100 \mathrm{~V} / \mathrm{div}, \mathrm{I}_{\mathrm{RES}} 1\right.$ A/div, HSG/LSG 5 V/div with $200 \mathrm{~ns} /$ div).

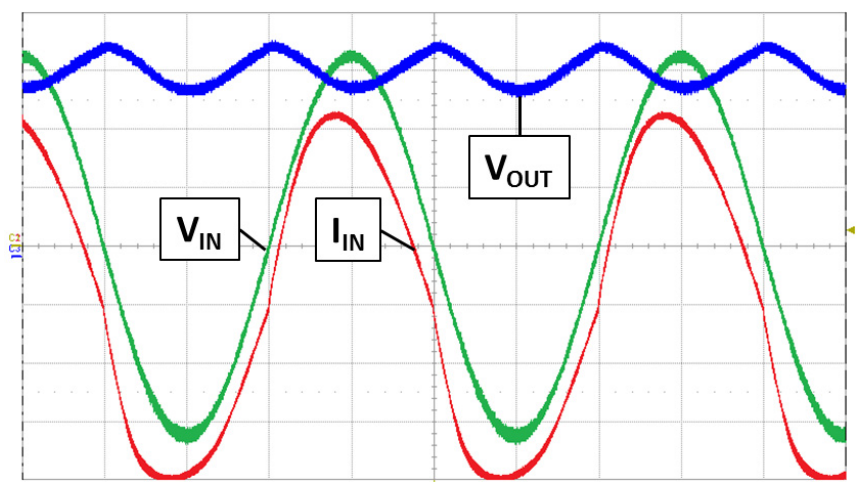

Fig. 11. Scope image for the input voltage, current, and output voltage. $\left(\mathrm{V}_{\mathrm{IN}}\right.$ $100 \mathrm{~V} / \mathrm{div}, \mathrm{I}_{\mathrm{IN}} 100 \mathrm{~mA} / \mathrm{div}, \mathrm{V}_{\text {OUT }} 100 \mathrm{~V} / \mathrm{div}$ with $5 \mathrm{~ms} / \mathrm{div}$ ). 
An AC $100 \mathrm{~Hz}$ ripple of $40 \mathrm{~V}$ is measured on the output voltage, which is about $13.3 \%$ of the average output voltage and can be reduced through the incorporation of a larger DC energy storage capacitor, depending on the specification of the following DCDC converter stage.

Fig. 12 shows the input current harmonics distribution at full-load operation, where a THD of $8.6 \%$ is measured. Since one of the potential applications for the proposed converter is the rectifier stage in LED drivers, the figure compares the harmonic magnitudes against the IEC 61000-3-2 standard class$\mathrm{C}$ device limits [6][7], where it is shown that the measured harmonics magnitudes are substantially lower than the limits set by the standard.

Fig. 13 shows a thermal photograph for the prototype under full-load operation, where the inductor windings are the hottest element in the circuit, with a maximum temperature of $84.5^{\circ} \mathrm{C}$ (with airflow). That is due to the charge pump circuit operation, which requires the resonant tank to store both the energy from the input line as well as the energy to the load every switching cycle, resulting in additional current stress on the resonant inductor.

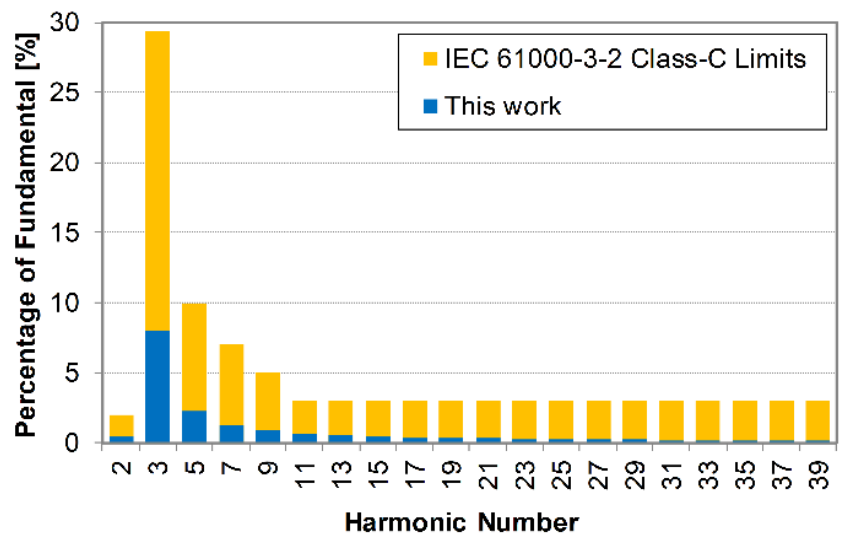

Fig. 12. Input current harmonics distribution against the IEC 61000-3-2 standard.

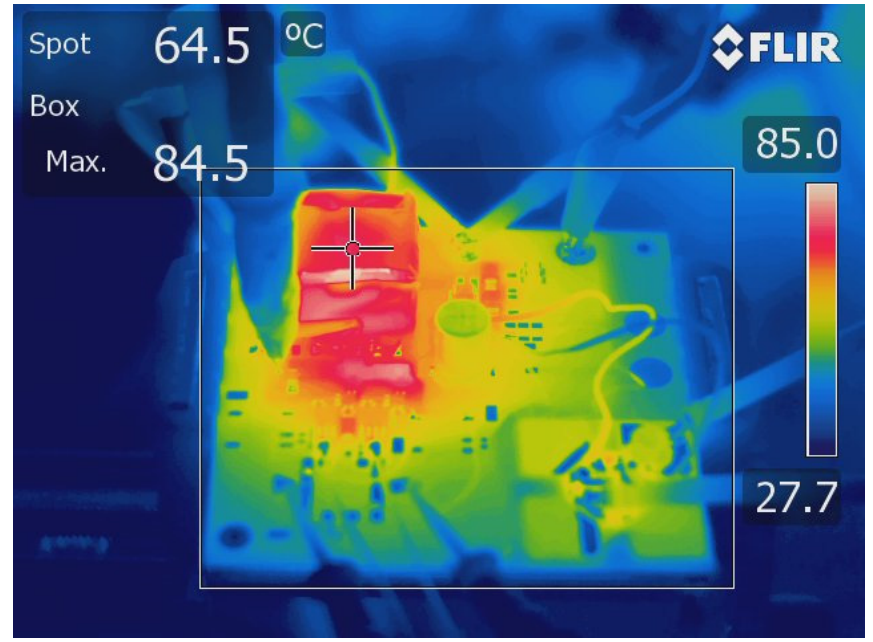

Fig. 13. Thermal image for converter at full-load.

\section{CONCLUSION}

A PFC rectifier for the AC-DC stage in single-phase offline converters is presented. With the addition of a charge-pump circuit comprised of a capacitor and a diode to the class-DE series-resonant converter, PFC functionality is achieved inherently, while operation is based on soft-switching, allowing for high frequency design. A $1 \mathrm{MHz} 50 \mathrm{~W}$ prototype employing WBG devices is designed and implemented, achieving a power factor of 0.99 and THD of $8.6 \%$ at an efficiency of $84 \%$, with input current harmonic magnitudes substantially lower than the IEC 61000-3-2 standard limit.

\section{REFERENCES}

[1] J. M. Rivas, R. S. Wahby, J. S. Shafran and D. J. Perreault, "New Architectures for Radio-Frequency DC-DC Power Conversion," in IEEE Transactions on Power Electronics, vol. 21, no. 2, pp. 380-393, March 2006.

[2] D. J. Perreault et al., "Opportunities and Challenges in Very High Frequency Power Conversion," 2009 Twenty-Fourth Annual IEEE Applied Power Electronics Conference and Exposition, Washington, DC, 2009, pp. 1-14.

[3] A. Knott et al., "Evolution of Very High Frequency Power Supplies," in IEEE Journal of Emerging and Selected Topics in Power Electronics, vol. 2, no. 3, pp. 386-394, Sept. 2014.

[4] A. Knott, T. M. Andersen, P. Kamby, M. P. Madsen, M. Kovacevic and M. A. E. Andersen, "On the ongoing evolution of very high frequency power supplies," 2013 Twenty-Eighth Annual IEEE Applied Power Electronics Conference and Exposition (APEC), Long Beach, CA, 2013, pp. 2514-2519.

[5] J. M. Rivas, D. Jackson, O. Leitermann, A. D. Sagneri, Y. Han and D. J. Perreault, "Design considerations for very high frequency dc-dc converters," 2006 37th IEEE Power Electronics Specialists Conference, Jeju, 2006, pp. 1-11.

[6] IEC 61000-3-2, Fifth Edition, International Electrotechnical Commission, 2018.

[7] EN 61000-3-2, European Committee for Electrotechnical Standardization, 2014.

[8] D. C. Marian, K. Kazimierczuk, Resonant Power Converters, 2nd edition. Wiley-IEEE Press, 2011.

[9] D. C. Hamill, "Class DE inverters and rectifiers for DC-DC conversion," PESC Record. 27th Annual IEEE Power Electronics Specialists Conference, Baveno, Italy, 1996, pp. 854-860 vol.1.

[10] W. Chen, F. C. Lee and T. Yamauchi, "An improved "charge pump" electronic ballast with low THD and low crest factor," in IEEE Transactions on Power Electronics, vol. 12, no. 5, pp. 867-875, Sept. 1997.

[11] Ferroxcube material datasheet https://www.ferroxcube.com/upload/media/design/FXCStainmetzCoeffi cients.xls.

[12] Micrometals material datasheet https://micrometalsarnoldpowdercores.com/pdf/mix/Mix-6DataSheet.pdf.

[13] E. Hoene, G. Deboy, C. R. Sullivan and G. Hurley, "Outlook on Developments in Power Devices and Integration: Recent Investigations and Future Requirements," in IEEE Power Electronics Magazine, vol. 5, no. 1, pp. 28-36, March 2018.

[14] G. Deboy, O. Haeberlen and M. Treu, "Perspective of loss mechanisms for silicon and wide band-gap power devices," in CPSS Transactions on Power Electronics and Applications, vol. 2, no. 2, pp. 89-100, 2017.

[15] A. Hopkins, N. McNeill, P. Anthony and P. Mellor, "Figure of merit for selecting super-junction MOSFETs in high efficiency voltage source converters," 2015 IEEE Energy Conversion Congress and Exposition (ECCE), Montreal, QC, 2015, pp. 3788-379. 